\title{
A poligraphia de Johannes Trithemius: reflexões acerca das relações entre Esoterismo e política nos séculos XV e XVI
}

\section{The Polygraphia of Johannes Trithemius: reflections on the relationship between esotericism and politics in the XV and XVI}

\author{
Francisco de Paula Souza de Mendonça Júnior \\ Doutor em História e Culturas Políticas, Universidad Federal de Minas Gerais, Belo Horizonte, Brasil, 2014. \\ Codiretor do CEEO-UNASUR. Contato: kirijy@gmail.com
}

DOI: http://dx.doi.org/10.15517/rehmlac.v8i1.24284

Fecha de recibido: 30 de noviembre de 2015 - Fecha de aceptación: 25 de febrero de 2016

\section{Palavras-Chave}

Johannes Trithemius, Polygraphia, Comunicação Secreta, Esoterismo, Política

\section{Keywords}

Johannes Trithemius, Polygraphia, Secret Communication, Esotericism, Politics

\begin{abstract}
Resumo
Este artigo debate o papel que a concepção esotérica de segredo teve na construção dos métodos de comunicação cifrada, buscando compreender como a concepção de que o mundo estaria repleto de signos secretos da mensagem deixada pelo Criador à sua criação ajudou a estes homens a forjar seus métodos de comunicação secreta, e, mais do que isso, ajudou-os a perceber a dimensão secreta não só da linguagem como também da ação humana. Tal empreitada é realizada através da discussão da obra Polygraphia, de autoria do abade alemão Johannes Trithemius (1462-1516), mantendo diálogo com outras obras pertinentes.
\end{abstract}

\begin{abstract}
This article discusses the role the esoteric concept of secret had in the construction of encrypted communication methods. We seek to understand the concept that the world is full of secret signs of the message left by the Creator to help His men forge these methods of secret communication. Furthermore , this secret communication helped them become aware of the secret dimension not only of language but also of human action. Thus this paper has been written whilst discussing the opus Polygraphia, written by a German abbot, Johannes Trithemius (1462-1516), it also maintains a dialogue with other relevant works.
\end{abstract}

No ano de 1508, já haviam se passado cinquenta e quatro anos desde que Johannes Trithemius havia nascido no vale do Moselle. Desde que ele havia abraçado a vida monástica sobre as direções de São Bento haviam se completado vinte e seis anos, sendo que vinte e cinco deles ele ocupou a posição de abade. Boa parte de um pouco mais de meio século de vida Trithemius foi empregada na busca daquilo que lhe foi uma grande paixão: o conhecimento. Para tanto conseguiu ao longo de seu período como abade no monastério de Saint Martin, em Sponheim, construir uma biblioteca que chegou a possuir 
um acervo de cerca de 2000 volumes, por volta de 1502. Apresentando uma qualidade pouco recomendada a um monge, quanto mais a um abade, Trithemius falou dela sem muita preocupação em esconder o orgulho que possuía de seu feito:

Nem vi em toda Germânia, nem ouvi tão rara, e tão prodigiosa Biblioteca, ainda que muitas tenha visto, onde seja tanta abundância de livros incomuns, em geral, mas raros, ocultos, secretos e prodigiosos e de tal natureza, qual fossem reencontrados com dificuldade em outro lugar ${ }^{1}$.

Por um lado Trithemius seguia as prerrogativas da Regra de São Bento, conforme a qual os monges deveriam dedicar parte do seu tempo à leitura, o que implicaria que o abade mantivesse uma biblioteca dentro do monastério. Entretanto, por outro, tal exigência beneditina possibilitou que ele continuasse perseguindo um objetivo que o acompanhava desde a infância, obter conhecimento. Sua biblioteca refletia isso, ainda que os catálogos tardios tenham se perdido, as referências em suas obras demonstram que o abade teve acesso a um variado espectro de temas e autores, incluindo alguns que parecem um tanto inesperados em um primeiro olhar. Conforme rastreou Coulianu ${ }^{2}$, Trithemius citou em seu Antipalus Maleficiorum, de 1508, diversas obras ligadas à magia e ao pensamento esotérico, como a Calvicula Salomonis, o Picatrix e o Sepher Raziel, dentre diversos outros. Isso nos parece um indicativo de que ele teve fácil acesso a estas obras, lembrando que seu Antipalus foi escrito após uma visita sua à biblioteca de Saint Martin.

Antes de retornarmos à vida do abade no ano de 1508, recuemos por volta de dois anos. Trithemius vivia momentos terríveis em Sponheim. Se em 1483 começava uma fase emblemática na vida de Trithemius, o ano de 1506 trazia um ponto final, bem como um recomeço. Sua situação à frente do monastério de Saint Martin havia se tornado insustentável e após um ano primeiro na companhia dos príncipes palatinos em Colônia, e posteriormente na companhia de Joaquim de Brandenburgo em Berlim, Trithemius viu-se obrigado a renunciar ao seu posto de abade em Sponheim, abandonando assim o trabalho de uma vida. Essa tempestade havia começado ainda em 1499, quando um descaminho fez com que sua carta endereçada ao seu amigo Arnold Bostius caísse nas mãos do prior do monastério de Ghent, onde seu confrade ${ }^{3}$ residia. Tal missiva falava de sua famosa Steganographia, arte pela qual Trithemius prometia a comunicação secreta à longa

\footnotetext{
${ }^{1}$ Nec vidi in tota Germania, neque esse audivi tam raram, tanque mirandam Bibliothecam, licet plures viderim, in qua sit librorum tanta copia non vulgarium, neque communium, sed rarorum, abditorum, secretorum mirandunque et talium, quales alibi vix reperiantur. Johannes Trithemius. Em: Ioan Coulianu, Eros and magic in the renaissance (Chicago: University Of Chicago Press, 1987), 166. [Tradução minha].

${ }^{2}$ Coulianu, Eros and magic, 167.

3 Juntamente com Bostius e Sebastian Brant (1457-1521), Trithemius fundou em 1497 a Fraternidade de Joaquim, cujo objetivo era defender a concepção imaculada da Virgem Maria por sua mãe, Sant'Ana. Coulianu, Eros and magic, 168.
} 
distância por meio de espíritos ${ }^{4}$. Principiou-se aí sua fama de demonomago, alcunha que ainda hoje lhe é conferida por algumas penas. Sua renúncia, porém, não se deu em função de tal polêmica, mas sim em decorrência de seu atrito com os monges de seu antigo monastério. Estes acusavam o abade de exigi-los para além do devido em suas tarefas no scriptorium, dada a sua paixão desmedida pelos livros. Possivelmente pela perseguição tanto interna quanto externa, Trithemius decidiu partir de Sponheim, deixando para trás sua biblioteca adorada. Ainda em 1506 ele tornou-se abade do monastério de Saint Jacob, em Wurzburg, onde permaneceu até sua morte, ocorrida no ano de 1516.

Retornemos ao ano de 1508 na vida de Trithemius. Já havia dois anos que ele fora forçado a trocar Sponheim por Wurzburg e somente naquele momento ele realizou a primeira das suas duas últimas visitas à biblioteca de Saint Martin. O agora abade de Saint Jacob tentou reaver algumas das obras que havia deixado para trás, ao menos aquelas em grego e hebraico, talvez as mais raras, porém estava velho e cansado demais para um recomeço. Contentou-se com duas visitas ao seu velho acervo, uma em 1508 e outra em 1515, já na soleira da morte. Trithemius não foi apenas um leitor ardoroso, mas também um escritor reconhecido entre os seus. Sua pena trilhou caminhos variados, da exortação aos escribas e a vida monástica aos temas esotéricos. Essa mudança na última porção da sua vida não esmoreceu seu ímpeto de escrever. Produziu em Wurzburg ao menos quatro de suas mais afamadas obras: o Liber Octo Quaestionum, o Antipalus Maleficiorum, o De Septem Secundeis e a Polygraphia. Obras de caráter variado, mas que dialogam com um tema em comum, a magia e a posição dos homens de poder ante a ela.

Sua obra mais polêmica, a Steganographia, como já foi dito, tratava da comunicação secreta e Trithemius resolveu retornar a este tema na Polygraphia. Pretendemos agora refletir sobre esse retorno do abade de Saint Jacob ao tema que trouxe perseguição e calúnia para ele, mas que também o tornou um homem ilustre em seu tempo. $\mathrm{O}$ ano de 1508 foi aquele no qual Trithemius concluiu sua obra Polygraphia, ao menos seu manuscrito, porque sua primeira versão impressa surgiria apenas em julho de 1518, por Johannes Haselberg, um livreiro de Haia, nos Países Baixos. Em 1561 Jacques Kerveur imprimiria em Paris a primeira tradução da obra em língua vernácula, realizada para o francês por Gabriel Coulanges ${ }^{5}$. Somente temos conhecimento das versões impressas da obra, não sabendo se uma versão manuscrita teria circulado e sobrevivido e, nesse caso, onde ela poderia se encontrar. A Polygraphia é composta de seis livros, mais a clavícula ${ }^{6}$. Cada um destes livros foi dedicado a uma técnica de comunicação secreta distinta, mas todas de alguma forma lidando com a ideia de cifragem por substituição, ou seja, os

\footnotetext{
${ }^{4}$ Noel L. Brann, Trithemius and Magical Theology: A Chapter in the Controversy over Occult Studies in Early Modern Europe (New York: State University of New York Press, 1999).

${ }^{5}$ Trabalhamos com digitalizações destas duas edições impressas, a latina e a francesa.

${ }^{6}$ A tradução para o francês consta apena de cinco livros, uma vez que o Gabriel Coulanges suprimiu o segundo livro do original latino.
} 
elementos da mensagem original são substituídos por outros, sendo a relação de substituição entre os elementos originais e os criptográficos de conhecimento apenas do autor da mensagem e do indivíduo a quem ela se endereça. Debrucemo-nos mais demoradamente sobre essa obra.

\section{Em busca de uma escrita mística, bela e secreta:}

\section{A Polygraphia de Trithemius}

No primeiro livro Trithemius apresenta trezentos e oitenta e seis colunas organizadas em pares, estando distribuídas em cento e noventa e duas páginas, totalizando nove mil, duzentos e sessenta e quatro vocábulos. Cada coluna é composta de vinte quatro letras, sendo a última o $\mathrm{W}$ ou duplo $\mathrm{V}$, como nomeia o abade. A inserção do $\mathrm{W}$ no alfabeto latino adotado por Trithemius teve uma dupla justificativa: por um lado o abade afirmou que cada coluna deveria conter vinte e quatro letras para que o método fosse funcional, e por outro o W seria uma letra de uso recorrente na língua alemã, conforme informou o próprio Trithemius ${ }^{7}$. Cada coluna era na verdade uma "dupla coluna", uma vez que continha a associação de uma letra (grammata) a uma palavra latina (paraphrasmata), indicando assim sua relação direta. A mensagem secreta deveria ser escrita da seguinte maneira: o operador deveria escolher a palavra mais apropriada de cada coluna, em sequência, de cada uma das trezentas e oitenta e seis colunas, retornando à primeira delas e repetindo o processo quantas vezes fossem necessárias. As letras (grammata) seriam escolhidas de forma que o texto original (mônada) pudesse ser desmembrado em outro (binário), por substituição de cada letra por seu equivalente na respectiva coluna. Em hipótese alguma ele deveria escolher mais de uma palavra por coluna ou mesmo saltar alguma coluna, pois se assim procedesse provocaria a falha de sua escrita secreta. Procedendo da maneira correta garantiria que a mônada, a mensagem secreta, fosse compatível com seu binário, a mensagem aberta. Caso observasse todas essas regras, este operador garantiria o sucesso da "operação cabalística", como classificou Trithemius ${ }^{8}$.

$\mathrm{O}$ abade descreve tal operação como uma forma da noite ocultar o dia, onde a primeira se refere ao binário e à segunda à mônada. Ele chega a alertar inclusive de que existe o risco das trevas noturnas dominarem o esforço dessa escrita secreta, mas que o homem realmente versado nessa arte é capaz de fazer que as luzes do dia iluminem as trevas, em qualquer que seja a situação ${ }^{9}$. É recorrente essa associação entre trevas e

\footnotetext{
${ }^{7}$ Gabriel Coulanges em sua tradução substituiu o W pelo \&, que significaria "et". A justificativa permaneceu a mesma: a necessidade de vinte e quatro letras para o sucesso do método da Polygraphia e a recorrência do "et" na língua francesa.

8 Johannes Trithemius - Polygraphiae libri sex, Ioannis Trithemii Abbatis Peapolitani, quondam Spanheimensis, ad Maximilianum Caesarem (Oppenheim: Haselberg, 1518), 22-23.

${ }^{9}$ Trithemius, Polygraphiae, 23.
} 
segredo, bem como entre a luz e o mistério revelado. Em seu Magia Naturalis, Giambattista della Porta $^{10}$ fala de formas de escrita invisível que somente seriam perceptíveis à noite. A associação soa um tanto óbvia, uma vez a noite traz consigo a diminuição ou ausência de luminosidade, e a consequente impossibilidade de se enxergar com clareza, porém tal relação vinda da pena de um homem como Trithemius tem mais significado. Lembre-se que o abade esteve envolvido com o pensamento esotérico que circulou nos séculos XV e XVI, logo a noite tornava-se mais significativa. Ela era o momento da observação astrológica, da realização dos rituais ou simplesmente onde estes homens poderiam encontrar a paz necessária para buscar a fagulha de divindade que repousava dentro deles, como proclamou o arauto hermético. Assim, a noite é o momento de lidar com o segredo, seja desvendando-o ou dando-lhe mais uma demão de sombra.

Trithemius disse que o sucesso do método criptográfico proposto nesse primeiro livro se basearia não apenas na expertise do operador, mas também no cuidado deste em indicar ao seu destinatário, binário ou cabalístico, o método empregado. $\mathrm{O}$ abade aponta que sem uma chave que permitisse a adequada decriptação, a mensagem real ou mônada jamais poderia ser descoberta senão por aquele que a escreveu ${ }^{11}$. Eis aqui mais uma vez manifesta o orgulho do abade, ainda que o tenha feito de forma oblíqua, pois ele acredita e afirma que seu método seria intransponível, a menos que o leitor dispusesse da correta relação entre grammata e paraphasmata.

Na clavícula que Trithemius ${ }^{12}$ escreveu para esclarecer sua Polygraphia, muito provavelmente numa atitude que buscava evitar as polêmicas nas quais se envolveu em função de sua Steganographia, ele apresentou quinze regras para a boa e precisa operação do método proposto neste primeiro livro da Polygraphia. Em sua maioria elas repisavam ideias recorrentes, como o cuidado ao selecionar os paraphrasmata, que não se deveria escolher mais de um de cada coluna ou menos saltar colunas ao escolhê-los, enfim reforçava ideias já apresentadas ao leitor. Porém algumas dessas regras tratam de temas específicos, o que apresenta preocupações muito reveladoras por parte do abade. A oitava regra afirma que para a realização dessa "escrita mística" o autor deveria possuir uma cópia bem feita da Polygraphia. Já a décima segunda regra afirmava que dada à versatilidade deste método os reis e príncipes poderiam possuir formas de escrita secreta para cada um de seus comandados ou amigos, garantindo assim que os interesses reais pudessem ser mantidos em segredo mesmo quando o rei estivesse tratando com os seus homens de confiança. Na décima quarta regra Trithemius ${ }^{13}$ alegou que sua Polygraphia continha uma série de influências da medicina, da matemática e da astronomia, e mais do que isso, que

\footnotetext{
${ }^{10}$ Giambattista della Porta. Magiae naturalis, sive de miraculis rerum naturalium libri IIII (Antuerpiae: In aedibus Ioannis Steelsii, 1562), 51.

${ }^{11}$ Trithemius, Polygraphiae, 23.

12 Trithemius, Polygraphiae, 524-528.

${ }^{13}$ Trithemius, Polygraphiae, 527.
} 
ela estaria relacionada com os santos, todas as coisas visíveis e invisíveis, área de atuação da magia natural.

O segundo livro da Polygraphia repetiu o mesmo método de escrita secreta, baseado na relação de transposição entre grammata e paraphrasmata ${ }^{14}$, distribuídos ao longo de cento e cinquenta e três páginas, em trezentos e oito colunas, mais uma vez duas colunas por página, totalizando sete mil, trezentos e noventa e dois paraphrasmata. Este livro tem como peculiaridade ter sido suprimido da tradução francesa da Polygraphia. Este fato aparentemente banal e sem maior importância, pode na verdade ser revelador da forma como a obra foi recebida e quais intenções moveram Gabriel de Coulanges a traduzi-la.

A grande originalidade do segundo livro foi Trithemius tê-lo composto de forma a aproveitar as palavras de importantes orações do universo católico. Conforme ele disse, não haveria uma forma mais discreta de enviar suas mensagens secretas.

Em uma única narração pode ser discernida [a] evidente diversidade que nasce de [uma] oração, desde que seja construída sobre nosso senhor fillho de Deus, [e] esta em verdade seja elevada à mãe dele sempre intacta virgem. Estão, porém, no segundo livro trezentos e oito palavras do alfabeto pela ordem colocada à frente, também sobre diversas matérias. Com efeito, em princípio o discurso narrativo seja dirigido para a própria nossa senhora, depois seja ampliado sobre os vinte e quatro alfabetos da oração dominical, em seguida seja submetido à salvação angélica, consequentemente a Salve Rainha, e finalmente a breve oração da [Sant'] Anna, santa mãe da virgem Maria mãe de Deus ${ }^{15}$.

Se o primeiro livro continha paraphrasmasta mais voltadas à composição de textos dedicados aos interesses mais imediatos da política, este segundo está voltado aos aspectos mais espirituais do mundo cristão. Assim estavam devidamente contemplados na Polygraphia tanto os interesses políticos do Trithemius sempre próximo dos príncipes do palatinado e interessado em fazer-se próximo ao imperador do Sacro Império RomanoGermânico, como também os interesses do abade Trithemius, conhecido exortador da reforma monástica e dos valores da vida monacal. Se assim os interesses do abade estavam contemplados, para Coulanges não se deu da mesma forma. Entendemos como plausíveis, e não excludentes entre si, duas explicações para que ele tenha suprimido o segundo livro de sua tradução. Em primeiro lugar esse livro não acrescentava nada de novo em termos de técnica de comunicação secreta, uma vez que era a repetição do que Trithemius havia

\footnotetext{
${ }^{14}$ Trithemius, Polygraphiae, 528.

${ }^{15}$ In sola narratione orationis menifeste diuersitas orta cernitur, quoniam illa de domino nostro Dei filio componitur, ista uero ad matrem eius sempre intactam uirginem eleuatur. Sunt autem in secundo libro dictionibus alphabeta per ordinem praeposita octo et trecenta, sub diuersis tamen materiis. Nam a principio narratio sermonis ad ipsam dominam nostram dirigitur, postea oratio Dominica sub alphabetis uigintiquatuor ampliatur, deinde saluatio subiicitur angélica, consequenter Salue Regina, et postremo breuis oratio de sancta matre uirginis Mariae dei parentis Anna. Trithemius, Polygraphiae, 528. [Tradução minha].
} 
proposto no primeiro, sendo provável que ele tenha considerado que seria melhor suprimilo a fim de não cansar o leitor com a repetição enfadonha de uma mesma técnica de escrita. Em segundo lugar, e o que consideramos mais decisivo em sua opção, tem-se aquilo que Trithemius via como um trunfo desse segundo livro, ou seja, o caráter essencialmente religioso dos paraphrasmata. A tradução para o francês foi oferecida a Carlos IX da França (1550-1574), o que fica claro na dedicatória da obra, onde ele elogia as qualidades do rei francês, que teriam sido compartilhadas pelo seu irmão, o então falecido Francisco II (1544-1560), bem como a utilidade dessa obra para as necessidades do monarca. A tradução foi publicada em 1561, ano em que foi Carlos foi coroado rei de França, com apenas onze anos. Entendemos que Gabriel Coulanges buscou ofertar ao jovem monarca um espelho de príncipe, a fim de ensinar ao jovem rei como utilizar o segredo a seu favor, bem como evitar que o mesmo segredo fosse utilizado contra ele. Desde o reinado de Francisco II a França se via envolta em conflitos religiosos, devido o crescimento do número de protestantes, especialmente na nobreza, e dos conflitos destes com os católicos. Parece-nos que Coulanges suprimiu o segundo livro da Polygraphia de sua tradução devido ao seu teor altamente relacionado com o culto católico. Buscava assim colocar a si e à sua obra fora desse conflito, o que poderia torná-los mais interessantes aos olhares da corte.

O método apresentado no terceiro livro repetia os procedimentos já aplicados nos dois livros anteriores. Mais uma vez, a mensagem poderia ser decifrada pela identificação da correta relação entre paraphrasmata e grammata. Neste terceiro livro, que correspondeu ao segundo na tradução de Coulanges, os paraphrasmata foram organizados em três colunas por página, ao invés de duas, o que totalizou cento e trinta seis colunas, num total de três mil duzentos e sessenta e quatro vocábulos. Trithemius afirmou que tais vocábulos seriam oriundos de línguas bárbaras, mas tudo indica que sua composição foi aleatória. Eles são compostos de um radical que é invariável na mesma coluna e de um sufixo ${ }^{16}$ que se alterna vinte e quatro vezes, como se o radical fosse declinado. Segue abaixo um exemplo da aplicação deste método.

Abrin madon badis, cadulur pasu, adin loroff masara damis, boda omo dromi drus uares mastron pha lares medas rassut madebor tara, mesen baiu phosat, galos, prosol fane lemoros, aroso cabil neso, hamol heliet rhamil fesia doron hubur rodex. Nesta narrativa de [um] falso sermão está contida essa breve sentença dos amigos

\footnotetext{
${ }^{16}$ Esse sufixo é composto por uma vogal e uma consoante, aparentemente escolhida por um processo que Trithemius chamou de orquemal, ou seja, elege-se uma sequência alfabética onde algumas letras são excluídas criando assim um "alfabeto alternativo". Por exemplo, a sequência da primeira coluna (abra, abre, abri, abro, abru, abras, abres, abris, abros, abrus, abran, abren, abrin, abron, abrun, abral, abrel, abril, abrol, abrul, abrax, abrex, abrix, abrox) segue essa lógica. O radical é $a b r$-, as cinco vogais se alternam como uma espécie de elemento de ligação entre o radical e a consoante final, e as consoantes $s, n, l$ e $x$ também se alternam. Assim surgem vinte e quatro paraphrasmata distintos para as vinte e quatro grammata, conforme exige o método da Polygraphia.
} 
informantes do perigo ao amigo: Não venha à cúria, porque o rei está indignado contigo $^{17}$.

O método apresentado no quarto livro é muito semelhante ao do terceiro livro. Mais uma vez os paraphrasmata foram organizados em três colunas por cada página, totalizando cento e dezoito colunas, dois mil oitocentos e trinta e dois paraphrasmata. Se nos livros anteriores da Polygraphia os grammata estavam representados numa coluna paralela a dos paraphrasmata, Trithemius propunha uma mudança. Agora os grammata já não mais estavam ao lado dos paraphrasmata, mas dentro deles, mais especificamente como sua segunda letra. Lembrando que permanece o aviso de que o uso ideal seria a escolha de um ou mais vocábulos por coluna, de forma sucessiva, utilizando quantas colunas forem necessárias, além de voltar ao começo delas se fosse preciso. Segue um exemplo de aplicação desse método.

Echorah hanasar dulay semalas, chorion suriel anephor schabaras, busarat uimaro tropon tumelech amasar. Para este intelecto secreto por todos os meios pegarei não mais que a segunda letra da dicção e descobrirás este sentido oculto, Evite este homem. Porque a segunda letra em Ecorach é c, em habasara a, em dulayu u, em semalas e. Junte estas quatro letras e farão a palavra, Cave [Evite] ${ }^{18}$.

O método proposto por Trithemius em seu quinto livro é baseado no que ele nomeou como tábua reta, tábua inversa e tábua orquemática. Tais tábuas são compostas por vinte e quatro colunas e vinte e quatro linhas. A primeira posição é ocupada pela letra $\mathrm{C}$, que funciona como um vértice do qual partem as demais linhas e colunas, para a tabela inversa a letra que ocupa essa função de vértice é a letra Y. Seguem as figuras que ilustram ambas tabulas.

\footnotetext{
${ }^{17}$ Abrin madon badis, cadulur pasu, adin loroff masara damis, boda omo dromi drus uares mastron pha lares medas rassut madebor tara, mesen baiu phosat, galos, prosol fane lemoros, aroso cabil neso, hamol heliet rhamil fesia doron hubur rodex. In hac narratione ficti sermonis haec breuis arcani sententia continetur amici de periculo auisantis amicum. Non uenias ad curiam, quia rex tibi indignatur. Trithemius, Polygraphiae, 530. [Tradução minha].

${ }^{18}$ Echorah hanasar dulay semalas, chorion suriel anephor schabaras, busarat uimaro tropon tumelech amasar. Pro huius intellectu mysterii de qualibet dictione secundam duntaxat literam accipito et inuenies hunc sensum latentem, Caue hunc uirum. Nam secunda litera in Ecorach est c, in habasara a, in dulayu u, in semalas e. coniunge has quatuor literas et facient hoc uerbum, Caue. Trithemius, Polygraphiae., 531. [Tradução minha].
} 
Figura 1

Tábua reta

\section{Recta tranfpofitionis tabula.}

a b c d e f g b i k l m n o p q r s t u $x y$; w

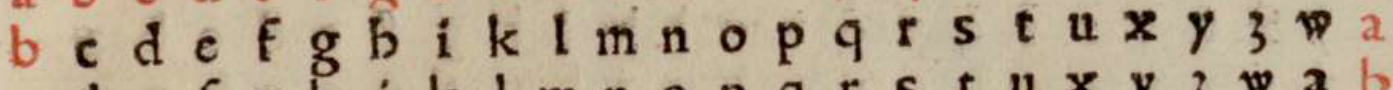

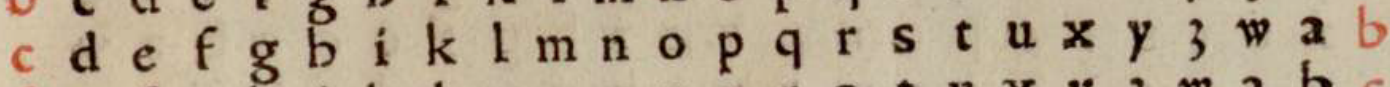

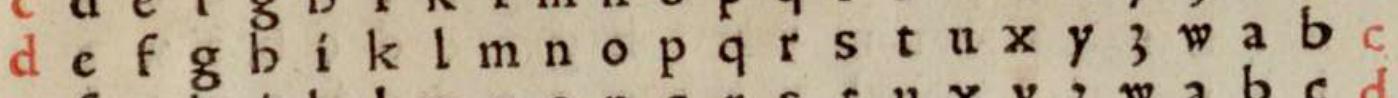
e f g b i k I m n o p r s t u $x$ y 3 w a b c d

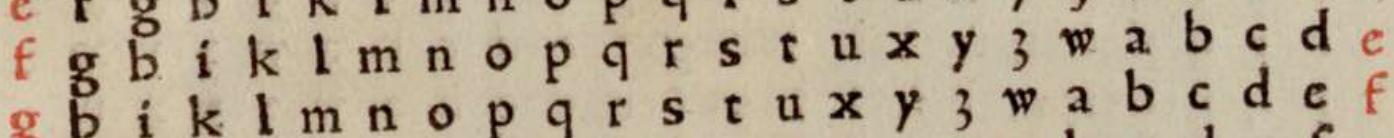
$\mathrm{g} b$ i k l m n p q r s uxy 3 wa b c def

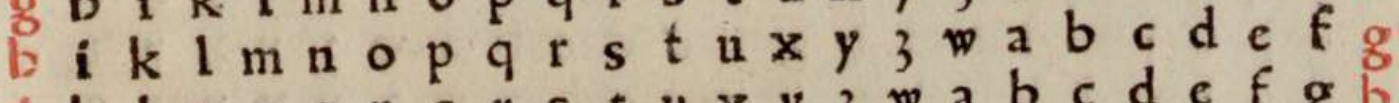
i $k 1 \mathrm{~m} \mathrm{n}$ o p q r s t u $x$ y 3 wa b c d e f g b

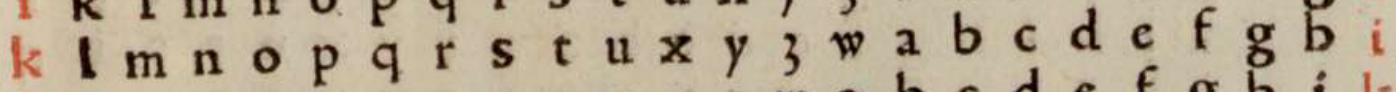

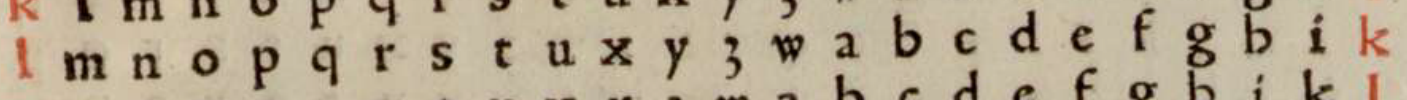
m n p q r s t u $x$ y 3 wa $b$ d e f g b i k I n o p a s t u $x$ y wa b c d e f g i k l m - p q r s t u $x$ y 3 wa b c e f g b i $k$ l m n

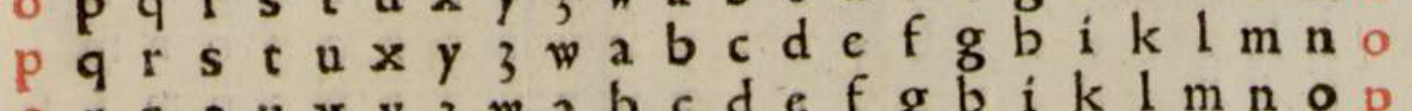

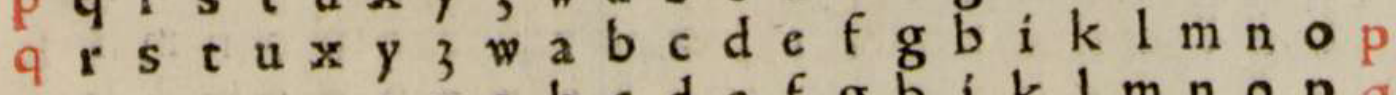
r s t u $x$ y 3 wa b c d e f g b i k l m n o p q s t u x y 3 wa b c d e f g b i k l m n o p q r t u $x$ y 3 wa b c d e f g i k 1 m no p q r s u $x$ y 3 w a b c d e f g b i $\mathrm{klm}$ n o p q r s t $x y$; w a c d e f g b i k l m o p q r s t u y 3 w a b c d e f g i $\mathrm{klm}$ n o p q s t u $x$

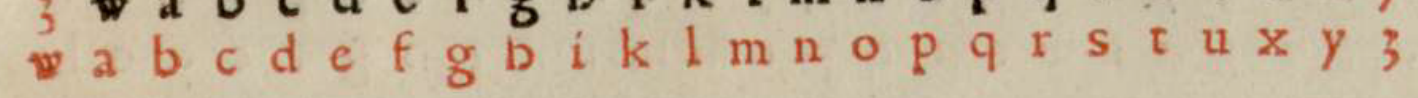

Fonte: Trithemius, Polygraphiae, 468. 


\section{Figura 2}

Tábua inversa

\section{Tabula tranfpofitionis auerfa.}

w 3 y $x$ ut s r q p o n m l k i b g f e d c b a

${ }_{3} y \times$ u $\mathrm{s}$ r q p o n m l k i b g f e d b a r

$y x$ u $t$ s $r$ q p o n m l k i b g f e d c b a w 3

x u t s r q p o n m l k i b g f e d c b a w 3 y

u. $\mathrm{s}$ r q p o n m l k b g t e d c b a w $3 y$ y

t s r q p o n m l k i b g t e d c b a w 3 y $x$ u

s r q p o n m l k i b g f e d c b a w 3 y $x$ u t

r q p o n m l k i b g f e d c b a w 3 y u t s

q p o n m l k i b g f e d c b a w $3 y \times$ u $\mathrm{t}$ s $\mathrm{r}$

po n m l k i b g f e d c b a w 3 y x u t s r

o n m l k i b g t e d c b a w 3 y $x$ u t s r $q$ p

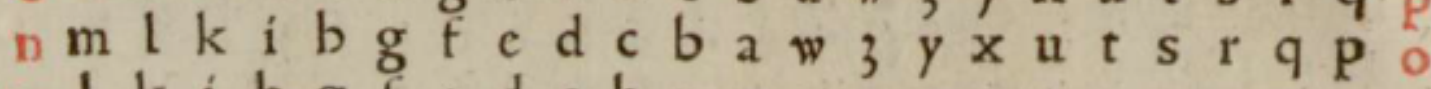

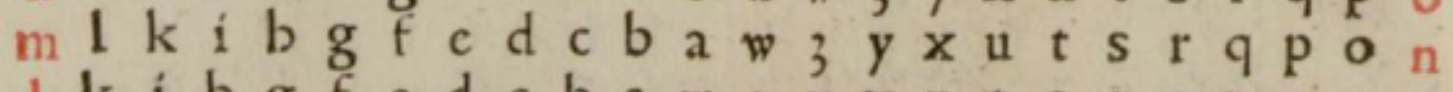

$\mathrm{l} k \mathrm{k} b \mathrm{~g} f \mathrm{c}$ e b a w 3 y $\mathrm{x}$ u t $\mathrm{s}$ r q p o n m

$k$ i b g f e d c b a w 3 y $x$ u t s r q p o n m l

i b g f c d c b a w 3 y $x$ u t s r q p o n m l k

b g f c d c b a w $3 y \times$ u t s r q p o n m l k i

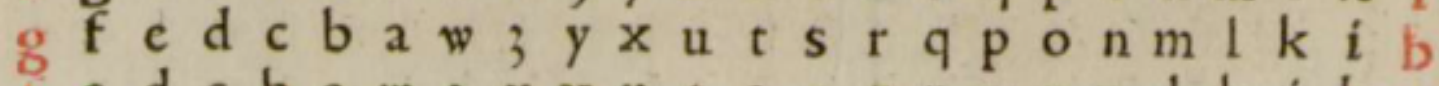

f e d c b a w ; y x u t s r p o n m l k i b g

c d c b a w $3 y \times$ u $\mathrm{c}$ s $\mathrm{r}$ q p o n m l k i b g f

d c b a w 3 y $x$ u t s r q p o n m l k i b g f e

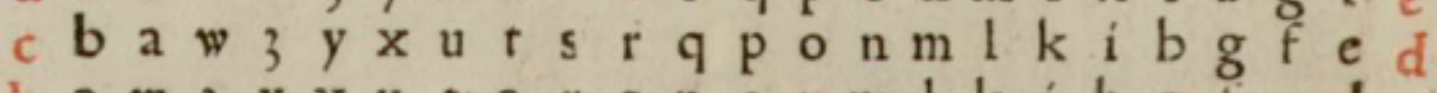

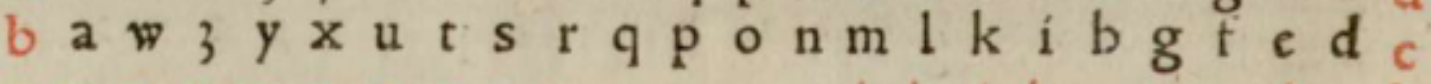

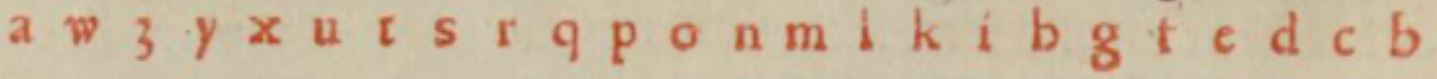

Fonte: Trithemius, Polygraphiae, 469.

O método de aplicação de tais tabelas é simples: se escreve uma coluna à esquerda em vermelho, contendo os vinte e quatro caracteres do alfabeto e outra à direita em negro, onde se deslocam em algumas unidades os caracteres do alfabeto. Estando assim grammata à esquerda e paraphrasmata à direita. É possível que as cores vermelha e negra escolhidas para as colunas sejam alusões ao dia e á noite, metáfora utilizada por Trithemius na obra 
para identificar a mensagem aberta e a mensagem criptografada. Por exemplo, tem-se $A=B$, $\mathrm{B}=\mathrm{C}, \mathrm{D}=\mathrm{E}$, e assim por diante. As possibilidades são muito grandes, considerando que a equivalência pode ser feita começando de qualquer letra do alfabeto. A única regra é que quando as letras coincidirem, a da coluna em vermelho com a da coluna em negro, elas devem ser eliminadas, para garantir o segredo da mensagem ${ }^{19}$.

Neste mesmo livro Trithemius também apresentou o que ele chamou de tábua orquemal, onde demonstrava mais um uso para a transposição via tábua reta ou inversa. Se nas tábuas reta e inversa se tratou de escolher uma letra pela qual começar a compor as colunas de equivalência, nessa tábua o abade ousou um pouco mais. Ele passou a agrupar os paraphrasmata em relação aos grammata ampliando o deslocamento entre um e outro através de um valor fixo. Não mais se tratava de deslocar os elementos da coluna em negro em uma posição em relação à coluna em vermelho, ele criou relações específicas para cada coluna. Como se pode ver na figura 3, Trithemius fez com que a primeira coluna em negro fosse escrita começando pelas letras "pares" e depois pelas "ímpares"; na segunda coluna elas foram escolhidas em intervalos de quatro posições a partir da letra $Y$, numa espécie de progressão aritmética; a última coluna começou com a letra $\mathrm{O}$ e seguiu o alfabeto até completar as vinte e quatro posições, e assim por diante. Trithemius propunha um sistema de comunicação secreta que buscava ser versátil e intransponível uma vez que o leitor não possuísse acesso à chave de leitura correta.

\footnotetext{
${ }^{19}$ Trithemius, Polygraphiae, 466-479.
} 
Figura 3

Tábua orquemal

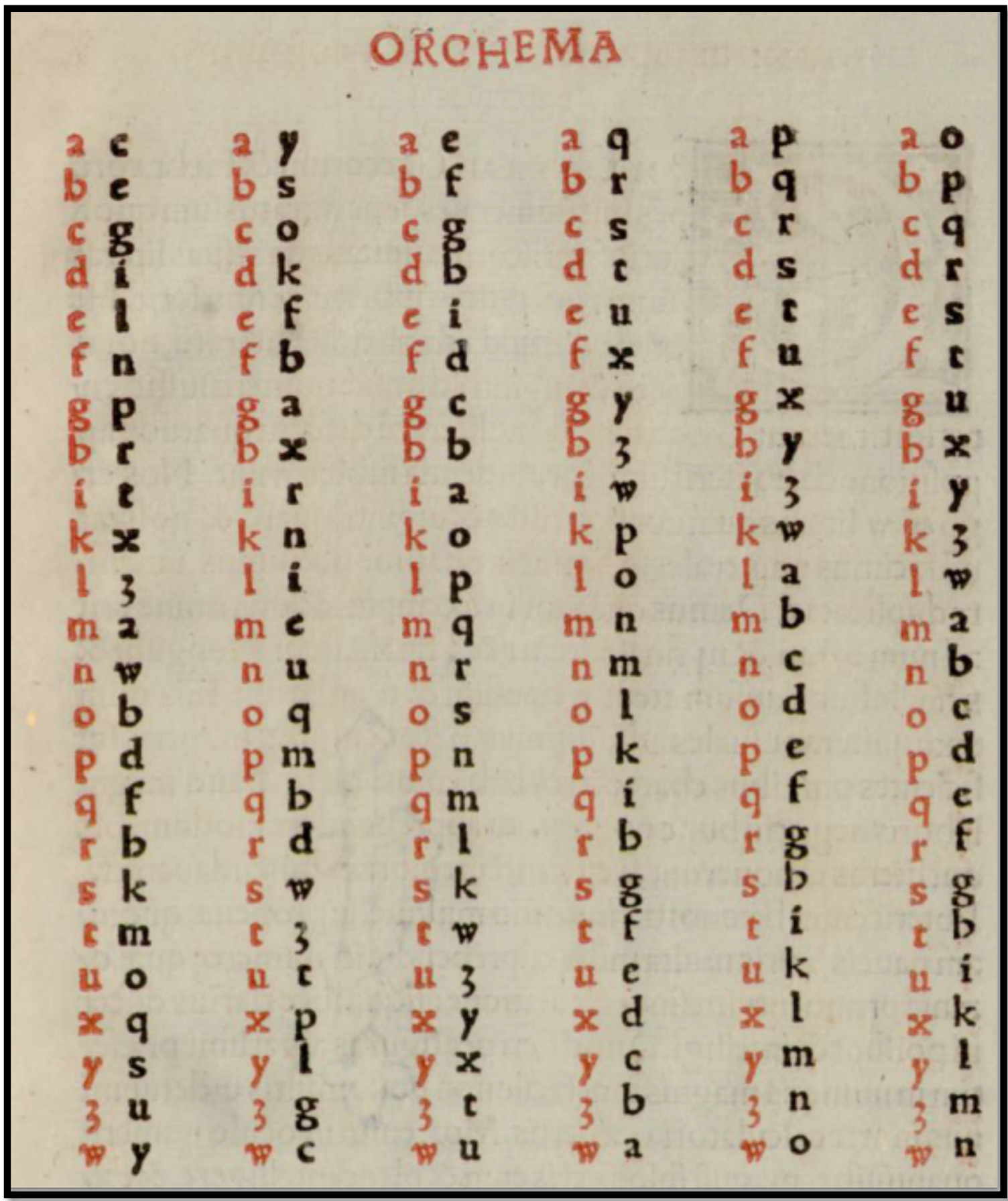

Fonte: Trithemius, Polygraphiae, 480.

Trithemius definiu o orchema como a operação onde não apenas ocorria a transposição de letras, mas também um salto. De origem grega, língua que fascinou a 
Trithemius, orchema teria como equivalência no latim a palavra transilitio, ação de passar ou de saltar por cima de algo, neste caso de algumas letras. Para o abade a comunicação secreta por meio dos orchema seria a mais segura de todas, além da mais versátil também ${ }^{20}$.

Fica cada vez mais claro que a Polygraphia possui uma ampla dependência do pensamento matemático, uma vez que está amplamente baseada em transposições e progressões aritméticas. Os séculos XV e XVI, tão marcados pelo redescoberta dos grandes autores da Antiguidade, também foram o palco da renovação do pensamento matemático, onde a abstração matemática passava a conviver com sua aplicação prática nos esforços de percepção do mundo sensível ${ }^{21}$. Senhor de uma imensa biblioteca, além de estar em contato com homens que viajaram para a Itália a fim de colocar-se em contato com as ideias que floresciam em Florença, como fizera seu amigo Johannes Reuchlin, Trithemius ${ }^{22}$ também reconheceu o valor da matemática, percebendo nela uma das grandes ferramentas para o indivíduo desejoso de dominar a arte proposta na Polygraphia.

No sexto e último livro Trithemius mostrou-se mais abertamente envolvido com temas de natureza esotérica. Ele partiu dos temas caros aos iniciados para buscar formas de comunicação secreta. Como primeiro tópico o abade debruçou-se sobre a astrologia. Segundo ele, os astros governariam o mundo dos homens por meio de suas influências astrais, o spiritus do qual tratou Ficino, se revezando no período de "trezentos e cinquenta e quatro anos lunares ${ }^{23}$, igualmente quatro meses, e ainda o mesmo número de dias e horas $^{24 "}$. O tema do governo astral é recorrente na obra do abade. Em 1499 ele já havia tratado disso em sua Steganographia, e em 1508 retornou a ele, de forma mais leve em sua Polygraphia e depois escreveu uma obra dedicada exclusivamente ao tema, o De Septem Secundeis.

Ao tratar do tema na Polygraphia, Trithemius colocou-se num ponto intermediário entre o que fez na Steganographia e o que faria no De Septem Secundeis. Se na primeira não esmiuçou a relação entre o governo dos astros e o mundo dos homens e na última desfiou cada conta desse rosário, na Polygraphia buscou apresentar uma síntese dessa sucessão planetária no governo universal, apontando as consequências dessas influências para a história da humanidade. O primeiro planeta a governar foi Saturno, seguido por Vênus, Júpiter e Mercúrio. É interessante que Marte tenha ficado de fora de sua síntese. O planeta era conhecido à época e Trithemius tratou dele e de suas influências na

\footnotetext{
${ }^{20}$ Trithemius, Polygraphiae, 533-534.

${ }^{21}$ Eugenio Garin, Ciência e vida civil no Renascimento italiano (São Paulo: Editora da Universidade Estadual Paulista, 1996).

${ }^{22}$ Trithemius, Polygraphiae, 481.

${ }^{23}$ Como ficará claro no De Septem Secundeis, Trithemius utilizou duas marcações de tempo: os anos lunares e os anos do Senhor. O primeiro serviria para marcar eventos desde o começo dos tempos, como a sucessão angélica, e o segundo a história propriamente cristã.

${ }^{24}$ annis lunaribus trecentis quinquaginta quatuor, mensibus item quatuor, ac diebus horisque totidem Trithemius, Polygraphiae, 486. [Tradução minha].
} 
Steganographia ${ }^{25}$, ao falar da perfeita conjunção astrológica para que se realizasse o aprendizado da Steganographia, e em seu De Septem Secundeis, ao tratar das influências deste astro, transmitidas e operadas por seu anjo, Samael. Ao excluir Marte, possivelmente Trithemius optou por não tratar de assuntos bélicos, temática associada ao planeta vermelho. Elemento importante dessa concepção de um governo planetário é a ideia que tal governo ocorreria por meio da ação de anjos associados a cada um destes planetas. Estes "anjos-planetários" seriam simultaneamente personificações da influência planetária, bem como agentes dessa mesma influência. Essa percepção remete à concepção do daimon hermético, figura importante na composição da imagem angélica no século $\mathrm{XV}^{26}$.

Trithemius começou essa síntese por Saturno. Sob o domínio deste astro, exercido por meio de seu anjo Orifiel, os homens teriam se tornado agricultores, caçadores, fundadores de cidades, e também rudes, silvestres, tristes e simples. Além disso, ter-se-iam mantido por toda a vida incultos e guiados unicamente pelos anseios da carne. O governo de Saturno e Orifiel foi substituído pelo governo de Vênus e de seu anjo Anael. Sob essa influência os homens se tornaram cultivadores e construtores de casas. Também seria durante esse período que teriam florescido diversas artes manuais, como a tecelagem e o lanifício. Os homens sob a atuação de Anael se tornaram ainda mais submissos à carne e à volúpia, e por isso resolveram tomar "belas esposas", com as quais tiveram muitos filhos. Também criaram jogos, cantigas, o canto e a cítara, o que mostrava também outra forma de apego à carne, de acordo com Trithemius. O terceiro planeta a governar foi Júpiter, também conhecido como Jove, e seu anjo Zachariel. Sob essa influência os homens teriam se tornado "inquietos de desejo" e mais dedicados à caça. Nesse período teriam começado a construir tendas e a se adornar com vestimentas variadas. Durante o reinado de Júpiter Trithemius afirma que teria sido maior o prejuízo para o reino de Deus, ocorrendo uma maior divisão entre os homens bons e os homens maus, entre aqueles que invocam a Deus e aqueles que estão presos ao mundo e à carne. A morte de Adão teria ocorrido nesse momento, como marca dessa crise.

O último governo planetário de que tratou Trithemius em sua Polygraphia foi o de Mercúrio e seu anjo Raphael, que teria começado no mês de fevereiro de 1055 e terminado em 1410. Este período guardou um momento de virada para a humanidade, uma vez que foi quando a literatura teria surgido. Trithemius afirmou que as primeiras letras teriam sido criadas a partir da observação de plantas, árvores e animais, possibilitando assim que alcançassem sua grande diversidade, além de permitir que o mundo se "ornasse de mais civilidade". Patrono dos poetas, Mercúrio por meio de Raphael ainda esconderia em suas fábulas promessas secretas. Essa ideia remete diretamente à concepção de segredo presente no pensamento de Trithemius, onde a comunicação escrita é capaz de ocultar segredos em

\footnotetext{
${ }^{25}$ Trithemius, Polygraphiae, 157-158.

${ }^{26}$ Bruce Gordon, The renaissance angel, em Peter Marshall e Alexandra Walsham orgs., Angels in the early modern world (Cambridge: Cambridge University Press, 2006).
} 
seu bojo. A criação das letras e da literatura marcaria também o fim do domínio da carne e da volúpia sobre os homens. O abade viveria sobre o próximo governo planetário, regido por Samael. Como apontou Trithemius ${ }^{27}$ em seu De Septem Secundeis se tratava do terceiro período de Samael. No primeiro havia ocorrido o dilúvio, no segundo houve a ruína de Tróia, assim surgia no horizonte a sombra da tragédia. Conforme Trithemius, no ano de 1508 restavam ainda dezessete anos da influência de Marte para afligir o reinado de Maximiliano I, e um dos objetivos de seu De Septem Secundeis foi instruir o imperador dos perigos representados pelas influências astrais, numa concepção de que a história é mestra da vida, logo o passado prepararia para enfrentar o presente por meio de seu exemplo.

Após essa síntese sobre a influência planetária ao longo da história humana, Trithemius retornou à comunicação secreta. Não existe um método proposto neste último livro que difira do que foi proposto nos demais livros, prevalecendo a regra geral da transposição entre paraphrasmata e grammata para se realizar a comunicação secreta. $\mathrm{O}$ que chama a atenção nesse livro é a variedade de alfabetos propostos, todos seguindo a regra de conterem vinte e quatro letras. Estes alfabetos mesclavam caracteres gregos e latinos, o que pode ser percebido mesmo naqueles que parecem inventados unicamente para o propósito da Polygraphia.

Ao apresentar o alfabeto que Honório Tebano, autor medieval relacionado à magia e a quem se atribui a autoria do Liber iuratus, Trithemius mostrou ideias interessantes. Primeiramente classifica tal alfabeto como parte de um conjunto de "tolices mágicas", porém ressaltou que o "ministério" de Honório Tebano estaria "escondido" em tais tolices. Trithemius teve acesso a tal alfabeto pelo trabalho de Petrus de Apono ou Pietro d'Abano autor do Heptameron, clara influência do De Septem Secundeis de Trithemius, bem como fonte da ideia de que o universo seria regido pela sucessão dos sete anjos-planetários presente na obra do abade alemão. Essa referência pode ser compreendida como uma crítica, mas entendemos como uma referência positiva. Se Honório ocultou seu conhecimento em "magicis fatuitates" assim também o teria feito Trithemius, e pensamos que a ideia aqui não é detratar a magia simplesmente, mas mostrar que em seu interior pode repousar conhecimento verdadeiro. Continuando, Trithemius se apoia em um autor que considera e estima, Pietro d'Abano, para tratar do alfabeto de Honório Tebano. E, mais uma vez a erudição de Trithemius acerca de temas esotéricos transborda, mesmo na Polygraphia, sua obra "livre dos equívocos da fé"28.

\footnotetext{
${ }^{27}$ Johannes Trithemius, Traité des causes secondes : précédé d'une vie de l'auteur, d'une bibliographie et d'une préface, et accompagné de notes (Paris: Chamuel Éditeur, 1897), 145-147.

${ }^{28}$ Trithemius, Polygraphiae, 498.
} 
Figura 4

Alfabeto de Honório Tebano

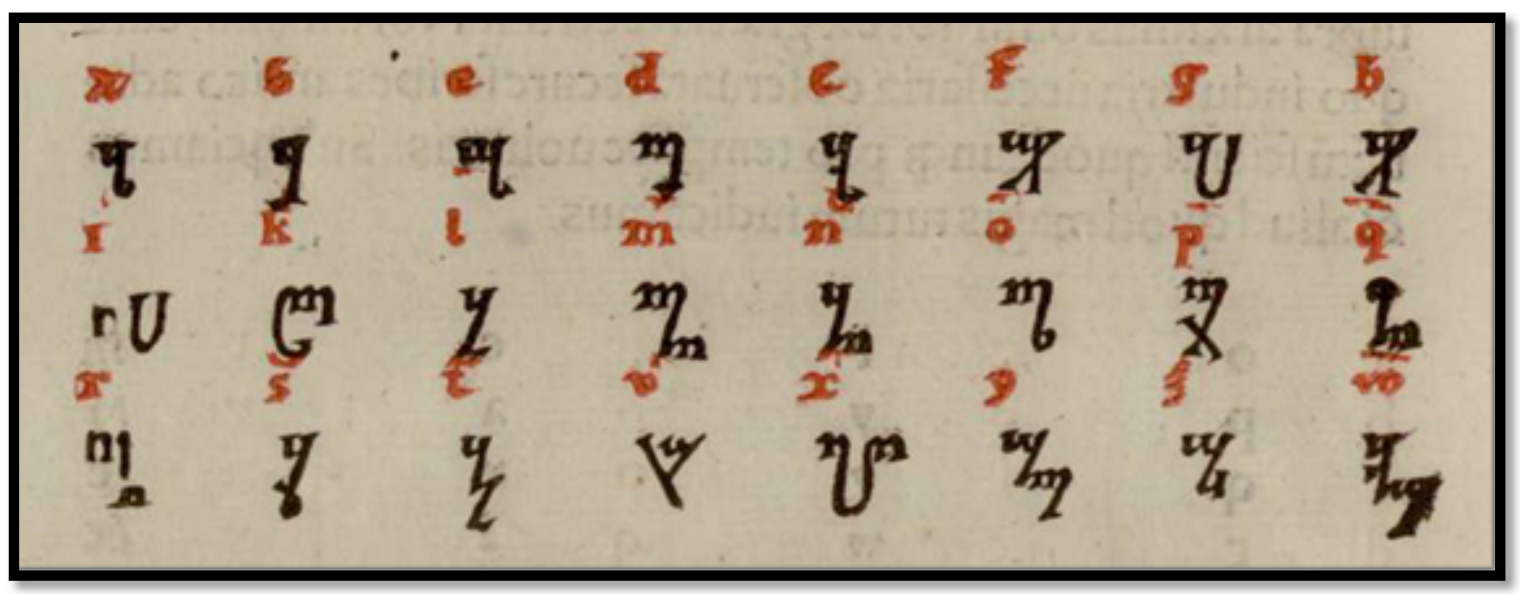

Fonte: Trithemius, Polygraphiae, 499.

Ao apresentar um alfabeto dedicado à alquimia, Trithemius aproveitou a chance para esclarecer sua opinião acerca desta disciplina. Como já havia alertado ao seu discípulo Johann Steinmoel $^{29}$, seria pecado se valer dos conhecimentos relativos à Ars Magna para obter facilidades na vida, como o enriquecimento sem esforço. Para Trithemius ${ }^{30}$ se envolver com a alquimia resultava em ruína física, moral e espiritual, devido à sua natureza traiçoeira. Nas palavras do abade ela prometia amar a muitos, porém mantinha-se casta. Esta amante ardilosa levava os incautos aos erros da mentira, vaidade e lascívia, resultando em desespero, pobreza e mendicidade. Assim sendo, a casta meretrix deveria ser evitada a todo custo, preservando assim os conhecimentos esotéricos para que sirvam de instrumentos da vontade do Senhor.

\footnotetext{
${ }^{29}$ Brann, Trithemius and magical theology, 103-104.

${ }^{30}$ Trithemius, Polygraphiae, 499.
} 


\section{Figura 5}

Alfabeto alquímico

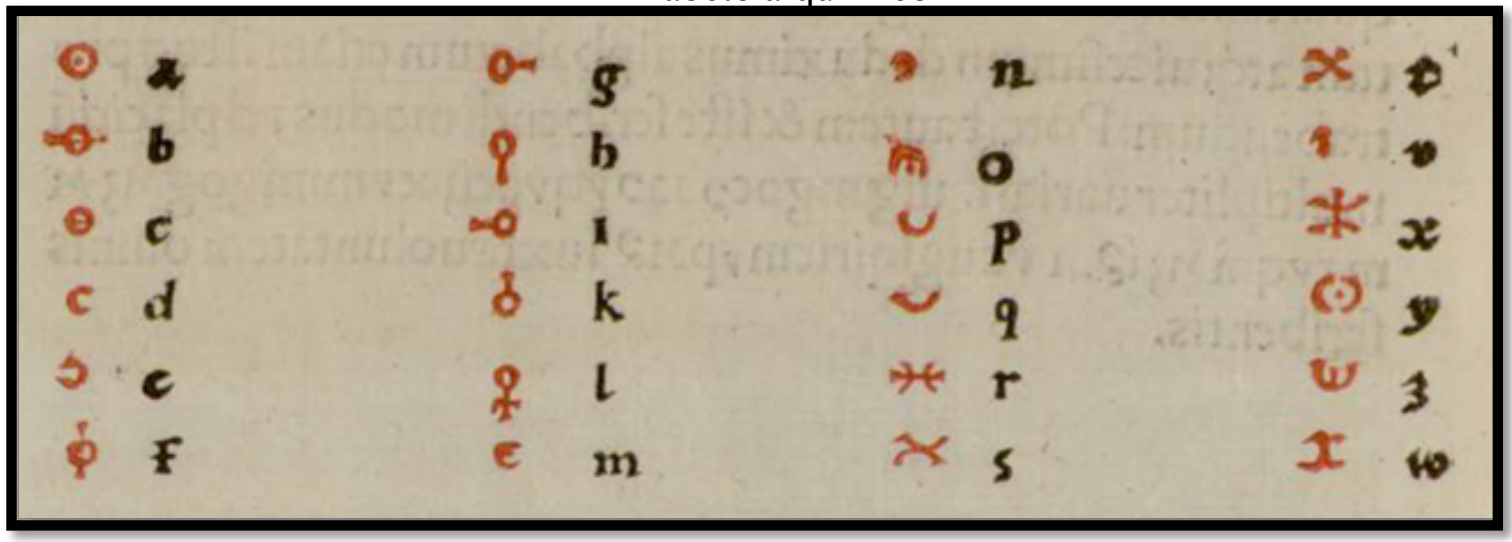

Fonte: Trithemius, Polygraphiae, 499.

\section{Considerações finais}

Em sua Steganographia e novamente em sua Polygraphia, Trithemius buscou mostrar que o uso de formas de escrita secreta ocorria desde a Antiguidade, encontrando nele mesmo um representante deste esforço antigo. Ele traça uma genealogia da comunicação secreta passando por grandes figuras históricas que trataram do tema, como César, Arquimedes, Cícero, Carlos Magno, Beda, Mathias Corvino, Pitágoras. Dessa forma, associados à comunicação secreta estavam imperadores, matemáticos, monges e reis que aplicaram a magia como ferramenta em seu reinado. E ele se colocava como sucessor legítimo destes homens, o herdeiro deste legado secreto. E tais personagens, assim como o próprio abade, se debruçaram sobre o tema da comunicação secreta com o objetivo de obter meios que os permitissem proteger seus assuntos dos olhares dos curiosos e dos inimigos, que poderiam agir como verdadeiros demônios ${ }^{31}$.

Ante uma ameaça tão grande contra os interesses do príncipe, Trithemius buscou ofertar uma ferramenta à altura da necessidade. Assim, sua Polygraphia seria capaz de tratar, de forma secreta e segura, dos mais variados temas que o bom governo exigia, versando sobre os quatro elementos, os rios, o reino vegetal, história e fábula, existência e inexistência, os homens e as bestas, o singular e o universal, tudo isso com honestidade e discrição $^{32}$. A capacidade do método proposto na Polygraphia seria tal que Trithemius chegou a afirmar: "Quem poderá enumerar as gotas do mar? E quem penetrará o inescrutável coração do homem?" 33 . A resposta que ele daria a sua própria indagação é simples: o indivíduo que dominasse aquilo que ele propôs em sua obra.

\footnotetext{
${ }^{31}$ Trithemius, Polygraphiae, 11.

${ }^{32}$ Trithemius, Polygraphiae, 220.

33 Guttas maris dinumerare quis poterit? Et cor hominis inscrutabile quis penetrabit? Trithemius, Polygraphiae, 221. [Tradução minha].
} 
Existe uma intenção central na obra de Trithemius em ajudar o homem bom a se defender do homem mau. É uma ideia que já estava presente na justificativa da criação da Steganographia ${ }^{34}$, e que volta ao cerne da motivação para a Polygraphia.

A real matéria à qual tratamos na Polygraphia, para a conveniência da coisa pública entre os homens bons é muito boa, útil e honesta, que portanto alistamos [uma] persuadida causa racional, a fim de que restituíssemos [os] homens bons em seus segredos, [que] um para o outro sejam anunciados todos os ministérios deles e seguros da investigação dos depravados. Em verdade nem os depravados assim como os perversos, que frequentemente também abusam das boas invenções, [mesmo] que fosse apresentada a ocasião que hão de ser enganados os mais simples, e menos cautelosos na apreciação das coisas, transmitimos modos místicos ou ocultos no qual há de ser escrito, oculto à qual a verdade envolta na medula escondemos na forma [de] algumas $\operatorname{coisas}^{35}$.

Embalado pelo desejo de evitar os olhares indesejados dos homens maus, capazes de utilizar sua arte para a ruína do bem comum, Trithemius uma vez mais teria recorrido aos escritos enigmáticos para proteger seu método do risco de cair em mãos erradas: "Sejam ocultados sob os mistérios enigmáticos: nem [os] bacuceus façam de qualquer modo manifestos os segredos das corujas" ${ }^{36}$. Porém, após todos os problemas que teve principalmente devido às acusações de Bovillus, o abade se preocupou em esclarecer ao leitor de suas reais intenções. Assim explica que toda a obscuridade que possa ser encontrada na Polygraphia seria uma forma de buscar garantir que o homem mau não a compreendesse, salvaguardando assim os interesses do homem bom, que coincidiam com a manutenção do bem comum. Trithemius afirmou ainda que toda acusação contra sua obra nada mais seria do que a prova da ignorância do leitor, que incapaz de compreender a essência do que ali era proposto acusava-lhe injustamente. Assim, Trithemius se defendia ao mesmo tempo em que desqualificava seus detratores, da mesma maneira que respondeu à Bovillus. Como complemento a esse discurso de defesa, Trithemius ainda compôs um autorretrato que corroborava sua argumentação.

\footnotetext{
34 Johannes Trithemius, Steganographie: Ars per occultam Scripturam animi sui voluntatem absentibus aperiendi certu (4to, Darmst. 1621), 3.

${ }^{35}$ Materia uero quam in polygraphia tractamus, ad reipublicae commodum inter uiros bonos multum est bona, utilis et honesta, quam idcirco rationabili causa persuasi conscripsimus, ut eius ministerio bonos homines in suis arcanis alterutrum nunciandis tutos et securos a prauorum inuestigatione redderemus. Verum ne prauis atquae peruersis, qui bonis etiam frequentius abutuntur inuentis, occasio praeberetur decipiendi simpliciores, minusquae cautos in aestimationem rerum, modos in ea scribendi mysticos tradidimus siue occultos, latentem quae in medulla ueritatem tegumentis quibusdam operuimus figurarum. Trithemius, Polygraphiae, 516. [Tradução minha].

36 Celantur sub aenygmatibus mysteria: ne bacuceis fiant bubonum arcana quomodolibet manifesta Trithemius, Polygraphiae, 16. [Tradução minha].
} 
Sou com efeito cristão, sou presbítero sob a norma do divino pai [São] Bento e monge: eu amo a Cristo, e já que posso com sinceridade de mente adoro sempre devoto: não existem para mim, não existiram, e [por] Deus protetor não existirão comércios com demônios: nenhuma em magia, necromancia, ou estudos em arte profana: não [existem] ocupações, não [existem] documentos. Quem sobre mim sente de outro modo, sente mal, faz injúria, e defende [em] aberto a mentira de Bovillus ${ }^{37}$.

O discurso que Trithemius teceu para se defender não dialoga bem com aquilo que na prática apresentou em sua vida. Ele afirma que não possui nenhuma relação com "documentos de magia" quando em sua biblioteca em Sponheim havia vários livros acerca do tema, e ele mesmo escreveu obras de cunho mágico, como o De Septem Secundeis. Além de sua inteiração com importantes nomes do esoterismo de sua época, como Cornelius Agrippa. Acreditamos que ao escrever essa defesa, o abade tivesse em mente expressamente a acusação que sofreu de Bovillus, a de ser um demonomago. Havia nos séculos XV e XVI uma percepção que diferenciava a magia natural e a demonomagia. Homens como Ficino, Pico e Girolamo Cardano ${ }^{38}$ viam a magia natural como honesta e pia, uma forma legítima de entrar em contato com o mundo natural e por meio dele obter contato com o Criador, influencia oriunda da cabala e do hermetismo. Porém, estes mesmos homens viam com horror e repúdio o comércio com espíritos malignos, ligando tal prática à superstição e à ignorância. Trithemius pensava da mesma forma. Exortou Maximiliano I a combater as feiticeiras e dedicou ao mesmo algumas obras de magia. Portanto, acreditamos que sua defesa se alicerce na refutação de seu comércio com espíritos malignos, e não em uma negação em relação à magia. Nas páginas de sua obra o abade teria tratado apenas com anjos, prática que não agredia a ortodoxia católica da época. De fato, era um momento no qual florescia o culto angélico. Dessa forma, ele negava praticar a magia de uma forma negativa, voltada à demonomagia e à necromancia, mas não a negava a Ars Notoria propriamente. Por mais que o abade tenha insistido que sua Polygraphia era uma obra totalmente desvinculada da magia, vários conceitos de origem mágica permeiam-na. $\mathrm{O}$ conceito matemático da mônada, o um indivisível, era percebida na época como uma ideia carregada de noções místicas, que dialogavam diretamente com o hermetismo, por exemplo, onde existe a ideia de que todo o mundo criado se origina e retorna ao Criador, o que formaria assim um conjunto único e indivisível.

\footnotetext{
${ }^{37}$ Sum etenim christianus, sum presbyter sub norma divi patris Benedicit et monachus: christum diligo, : nulla mihi sunt, nulla fuerunt, et protectore deo nulla erunt cum daemonibus commertia: nulla in magicis, necromanticis, seu profanis artibus studia: nullae occupationes, nulla documenta. Qui de me aliter sentit, male sentit, iniuriam facit, et apertum Bouilli mendacium defendit. Trithemius, Polygraphiae..., p.16. [Tradução minha].

${ }^{38}$ Stuart Clark, Pensando com demônios: a ideia de bruxaria no princípio da Europa Moderna (São Paulo: Edusp, 2006).
} 
O conteúdo esotérico no texto de Trithemius não é uma finalidade, mas na verdade um instrumento. Ao menos parte de sua vida adulta o abade viveu em contato com o imperador e os príncipes eleitores, e foram frequentes seus esforços em oferecer-lhes instrumentos e conhecimentos que lhes fossem úteis para a prática do bom governo, sendo a Polygraphia mais um desses esforços. Dedicada a Maximiliano I, a quem Trithemius ${ }^{39}$ chamou de "imperador do mundo", a Polygraphia tinha claro o objetivo de oferecer aos homens bons um instrumento por meio do qual pudessem comunicar seus assuntos reservados aos amigos, de forma discreta e segura. Para Trithemius os homens bons poderiam estar entre os laicos ou os clérigos, mas principalmente entre reis e príncipes, homens que ele entendia como mais capazes de atuar para salvaguardar os interesses da cristandade $^{40}$. Dada a missão que percebia atribuída ao imperador, salvaguardar o bem comum dos perigos causados pelos homens maus, Trithemius buscou oferecer uma ferramenta que julgou como a mais adequada para tal missão.

Donde seja necessário teu governo ó gloriosíssimo César Maximiliano, assim como vestir a pele hercúlea, e vibres a clava nas mãos, e foi dado a ti por Deus o empreendimento de purgar o mundo destes monstros [que o] assolam. Nunca existirá paz no reino [a menos que] sejam suprimidos os bacuceus do meio. Que perturbam a paz do reino, se esse reino demonstra [ter] inimigo. Estes são ladrões que assediam os caminhos itinerantes, pilham outros, dos quais hoje a terra está cheia, e jamais é segura a caminhada na estrada ${ }^{41}$.

Após todas essas considerações é o momento de retornar ao ano de 1508. Trithemius estava se estabelecendo em Wurzburg, como abade do monastério Saint Jacob. Era um homem experimentado, que já havia vivido muita coisa. Há longos quatro anos vinha se defendendo da acusação de Bovilus, que ainda que não tenha resultado em problemas com a Igreja, havia maculado sua reputação com a mancha da demonomagia. Era nessa altura um abade respeitado, um reconhecido exortador dos valores da vida monástica. Porém, estava acostumado à vida nas cortes, por mais que isso não condiga com sua condição de monge. Era próximo o bastante de Maximiliano I para escrever-lhe sobre variados assuntos, desde genealogia a combate às feiticeiras. Quando acusado de ter fraudado uma genealogia para agradar ao imperador, Trithemius viu-se livre de maiores incômodos, graças à intervenção do monarca. Quando sua relação com os monges de Saint Martin atingiu uma crise sem volta, foi entre os príncipes palatinos que ele encontrou

\footnotetext{
${ }^{39}$ Trithemius, Polygraphiae, 516.

${ }^{40}$ Trithemius, Polygraphiae, 517.

${ }^{41}$ Unde foret necessarium reipubliçe tuae o gloriosissime Caesar Maximiliane, ut pellem indueres herculeam, clauamquae uibrares in manibus, et seuis his monstris orbem tibi a deo purgares commissum. Numquam pax erit in regno nisi bacucei tollantur e medio. Qui regni pacem turbat, se hostem esse regnis demonstrat. Hi sunt latrones qui uias itinerantium obsident, rapiunt aliena, quibus hodie plena est terra, et nunquam tuta est ambulantibus uia. Trithemius, Polygraphiae, 522. [Tradução minha].
} 
abrigo e a posição de abade em Wurzburg. Por um lado, em 1508 Trithemius se via recomeçando sua trajetória como homem da Igreja, mas por outro lado viu sua relação com o imperador e os príncipes eleitores consolidada.

$\mathrm{O}$ ano de 1508 também teve outros significados para Trithemius. Foi o ano em que revisitou a biblioteca que ajudou a construir em Sponheim, e após esse reencontro escreveu obras marcantes sobre temas relativos à magia e à feitiçaria. Nessa fase de sua vida seu pensamento foi particularmente influenciado pelo Heptameron de Pietro d'Abano. Escreveu acerca da influência dos planetas no destino da humanidade, mais especificamente como os anjos associados a cada um dos planetas agia o spiritus destes astros sobre a vida dos homens. Conforme escreveu no seu De Septem Secundeis, o ano de 1508 estaria dentro do período regido por Marte, quando atuaria o anjo Samael pela terceira vez desde o princípio dos tempos. Cada período sob os auspícios de Samael teria sido marcado por uma grande tragédia, capaz mesmo de alterar os caminhos da humanidade. E, ao que tudo indica, Trithemius estava particularmente preocupado com isso.

Maximiliano I também vivia um ano especial em 1508. Apesar de estar no poder desde a morte de Frederico III, em 1493, somente quinze anos depois ele foi entronizado imperador do Sacro Império-Romano Germânico. E não foi gratuita a preocupação de Trithemius com as influências perigosas que vinham com Samael. Todo o governo de Maximiliano estava sob a influência de Marte, cujo terceiro ciclo havia iniciado em 1525. Conforme suas obras indicam, Trithemius esperava por uma mudança drástica no mundo que conhecia. No De Septem Secundeis chegou mesmo a falar que nasceria uma nova religião, remetendo ao sempre assustador tema do cisma e da queda da Igreja Romana. Mas o seu verdadeiro temor estava direcionado aos descaminhos que poderiam se abater sobre o imperador. É interessante que não mencione o papa, num ambiente de concorrência política entre Império e Papado. Porém, não pode sumir das vistas a proximidade entre Trithemius e Maximiliano I, bem como dos demais príncipes eleitores. Seja pela proximidade ou pelo fato de viver em territórios alemães, a queda do imperador e de suas cortes teria um efeito nefasto mais imediato nas ambições de Trithemius. Ele se encontrava distante do papa, mas suficientemente próximo do imperador e dos príncipes alemães para que isso the proporcionasse bons frutos, como proteção nas muitas polêmicas nas quais se envolveu ou mesmo o providencial cargo de abade em Wurzburg, em 1506.

Em 1508 Trithemius era um homem em um recomeço, seria desastroso que perdesse o apoio imperial ou dos príncipes em consequência da presença de Samael. Sendo assim, retomou seus esforços de fornecer meios para que estes príncipes pudessem enfrentar os tempos difíceis que ele acreditava estarem se aproximando. Desde a Steganographia ele acreditava que a comunicação secreta era a maneira mais eficaz de se evitar que os esforços dos homens maus prevalecessem sobre os interesses dos homens bons, ou melhor, as reviravoltas da Fortuna, causando o caos no reino e o prejuízo do bem comum. Nove anos após sua primeira empreitada na comunicação secreta, o abade retomou o tema, buscando 
livrar-se das polêmicas que macularam sua obra anterior, mas sem abandonar os conceitos que ajudaram em sua composição. O homem que escreveu a Polygraphia buscava ofertar a Maximiliano I uma ferramenta por meio da qual pudesse manter suas ações e interesses fora do alcance dos bacuceus, numa visão que demonizava os homens que perniciosamente atentavam contra o bem-comum. Se o De Septem Secundeis foi uma tentativa de alertar para os perigos de Samael e das demais influências planetárias pela descrição histórica dessa atuação, a Polygraphia foi um esforço de se evitar tais influências perigosas, ou melhor, de domá-las, numa atitude típica dos homens influenciados pelas ideias que floresciam na Itália do século XIV e que se espalhavam pela Europa.

Por meio de sua Polygraphia, Trithemius buscou que o segredo fosse utilizado como ferramenta de defesa dos interesses do imperador e dos príncipes, instrumentalizando o saber esotérico numa ferramenta política contra a ameaça das mudanças políticas que ele acreditava que seriam trazidas por Samael, anjo de Marte. Instrumento para a salvaguarda e garantia do bem comum, caso a Polygraphia e seus métodos de comunicação secreta garantissem que os interesses e o poder do imperador e seus príncipes fossem protegidos, Trithemius também resguardava a proteção que recebia desses. Conhecedor dos perigos que a Fortuna traz em seus descaminhos e antevendo uma mudança de consequências imprevisíveis, Trithemius buscou instrumentalizar os indivíduos que por várias vezes the haviam garantido providencial apoio. Certa vez o abade disse que os segredos ordinários cabiam apenas aos amigos ordinários e os segredos importantes aos amigos importantes, pois o homem que Trithemius era em 1508 mais do que nunca se viu interessado em proteger e manter-se próximo dos amigos importantes.

\section{Fontes Primárias}

Della Porta, Giambattista. La magie naturelle ou Les Secrets et Miracles de La Nature. Paris: H. Daraqon, Libraire-Editeur, 1913.

Della Porta, Giambattista. Magiae naturalis, sive de miraculis rerum naturalium libri IIII. Antuerpiae: In aedibus Ioannis Steelsii, 1562.

São Bento. Regra de São Bento. Rio de Janeiro: Edições Lumen Christi, 1992.

Trithemius, Johannes. Polygraphiae libri sex, Ioannis Trithemii Abbatis Peapolitani, quondam Spanheimensis, ad Maximilianum Caesarem. Oppenheim: Haselberg, 1518.

Trithemius, Johannes. Polygraphie et universelle escriture cabalistique de MJ Trithéme Abbé. Paris: Jacques Kerver Imprimeur, 1561.

Trithemius, Johannes. Steganographie: Ars per occultam Scripturam animi sui voluntatem absentibus aperiendi certu, 4to, Darmst, 1621.

Trithemius, Johannes. The steganographia of Johannes Trithemius. Edinburgh: Magnum Opus Hermetic Sourcebook, 1982. 
Trithemius, Johannes. Traité des causes secondes : précédé d'une vie de l'auteur, d'une bibliographie et d'une préface, et accompagné de notes. Paris: Chamuel Éditeur, 1897.

\section{Bibliografia}

Black, Antony. El pensamiento politico en Europa, 1250-1450. Cambridge: Cambridge University Press, 1996.

Borchardt, Frank L. The magus as Renaissance man. Sixteenth Century Journal, XXI, 1 (1990), 57-56.

Boudet, Jean Patrice e Julien Véronèse. Le secret dans la magie rituelle médiévale. Micrologus: Natura, Scienze e Società Medievali. Florença: SISMEL - Edizioni Del Galluzo, (2006), $\mathrm{n}^{\circ}$ XIV.

Brann, Noel L. The Abbot Trithemius (1462-1516): the renaissance of monastic humanism. Leiden: Brill, 1981.

Brann, Noel L. Trithemius and Magical Theology: A Chapter in the Controversy over Occult Studies in Early Modern Europe. New York: State University of New York Press, 1999.

Clark, Stuart. Pensando com demônios: a idéia de bruxaria no princípio da Europa Moderna. São Paulo: Edusp, 2006.

Corsetti, Jean-Paul. História do esoterismo e das ciências ocultas. Braga: Círculo de Leitores, 2004.

Culianu, Ioan P. Eros and magic in the renaissance. Chicago, University Of Chicago Press, 1987.

Faivre, Antoine. O Esoterismo. Campinas; São Paulo: Papirus, 1994.

Garin, Eugênio. Ciência e vida civil no Renascimento italiano. São Paulo: Editora da Universidade Estadual Paulista, 1996.

Gordon, Bruce. The renaissance angel. Em: Peter Marshall e Alexandra Walsham orgs. Angels in the early modern world. Cambridge: Cambridge University Press, 2006.

Kieckhefer, Richard. Magic in the Middle Ages. Cambridge [England]; New York: Cambridge University Press, 1989.

Kieckhefer, Richard. The specific rationality of medieval Magic. The American Historical Review 99, no. 3, (1994): 813-836.

Saraiva, F. R. Novísssimo dicionário latino-português. Rio de Janeiro/Belo Horizonte: Garnier, 2000. 